EISSN: 2706 -7947 ISSN: 2077- 4613

DOI: 10.36632/mejas/2021.11.1.18

Journal homepage: www.curresweb.com

Pages: 245-257

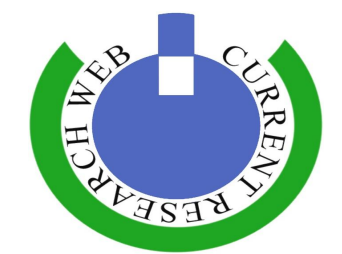

\title{
Investigation of the Effects of Gram -Negative Bacteria on the Immune Responses and Liver and Kidney Functions in Albino Rats
}

\author{
Amin, H.M. \\ Department of Zoology, Faculty of Science, Minia University, Minia, Egypt. \\ Received: 05 January $2021 \quad$ Accepted: 28 February 2021 Published: 10 March 2021
}

\begin{abstract}
Gram-negative bacteria can cause many serious infections, such as pneumonia, peritonitis, urinary tract infections, bloodstream infections and wound or surgical site infections. The present study aimed to demonstrate the role of Aeromonas hydrophila infection in innate and adaptive immune responses, lipid profiles and liver and kidney functions in male albino rats. Animals were divided into control groups that were injected intraperitoneally with saline solution $(0.9 \% \mathrm{NaCl})$ and treated groups that received daily intraperitoneal injection with $0.2 \mathrm{ml}$ of bacterial suspension containing $6 \times 10^{6}$ cells $/ \mathrm{ml}$ of $0.9 \%$ $\mathrm{NaCl}$. Rats were sacrificed at the days $4,8,12,16$ post-injection and the results indicated that bacterial infection induced alterations in most of the measured parameters. The biochemical changes recorded were characterized by decreased serum total proteins, albumin, urea, uric acid, AST, ALT and HDL cholesterol. On the other hand, remarkable increase was noticed in total lipids, total cholesterol and (LDL) cholesterol. Marked increase was noticed in total WBCs, monocyes, eosinophils, basophils neutrophils, phagocytosis in vitro and in vivo, PFC percentage, agglutination ratio, total immunoglobulin level. On the other hand, a marked decrease was noticed in lymphocytes percentage (lymphopenia), leukocyte migration inhibition factor (MIF) and Positive results of the precipitation test in all infected rats were recorded. Conclusion: From the previous results, we can conclude that Aeromonas hydrophila infection could affect the innate, cell-mediated and humoral immunity and liver and kidney functions in mammals. The complications accompanied with Aeromonas septicaemia may be attributed to the immunological and biochemical changes resulted from the bacterial infection, so, the use of immuno-modulator is necessary in treatment besides the antibacterial drugs.
\end{abstract}

Keywords: Gram-negative bacteria, immune system, liver and kidney functions, lipid profiles, albino rats.

\section{Introduction}

Gram-negative bacteria (GNB) are among the most significant public health problems in the world due to the high resistance to antibiotics. These microorganisms have great clinical importance in hospitals because they put patients in the intensive care unit (ICU) at high risk and lead to high morbidity and mortality (Batirel et al., 2011 and Hormozi et al., 2018, Carbapenem, 2017, Ruppé et al., 2015 and Carbapenem, 2019). These organisms have a range of mechanisms to prevent the action of many antimicrobials used in clinical medicine. Gram-negative bacteria can cause many serious infections in humans, including urinary tract infections, pneumonia, diarrhea, meningitis, sepsis, endotoxic shock, bloodstream infections, wound or surgical site infections, peritonitis and many others (Ruppé et al., 2015, Naas et al., 2016 and Hassan et al., 2020).

Gram-negative bacteria have two membranes. The external membrane expresses a potent immune response inducer, lipopolysaccharide (LPS), which is composed of three units: a hydrophilic polysaccharide, $\mathrm{O}$ antigen, and a hydrophobic domain known as lipid A. Lipid A is responsible for the higher endotoxic activity of these bacteria (Auer and Weibel, 2017). LPS can trigger the innate immune response through Toll-like receptors 4 (TLR4), which occurs in many immune cells such as monocytes,

Corresponding Author: Amin, H.M., Department of Zoology, Faculty of Science, Minia University, Minia, Egypt. E-mail: hananamin015@gmail.com 
macrophages, dendritic cells, and neutrophils. The resulting activation of the innate immune response mediated by LPS together with TLR4 receptors culminates in an exacerbated response with the production of cytokines, chemokines, and interferons. The response of the immune system depends on both the severity of the infectious process and the structure of the LPS in the aggressive bacteria (Livermol, 2012).

Aeromonas species are Gram-negative, facultative anaerobic bacteria, with a wide distribution in nature. These bacteria can grow and produce enterotoxin and hemolysin at refrigeration temperatures of $4^{\circ} \mathrm{C}$. Aeromonas species are significant potential agents in foodborne illnesses since they have been isolated from fresh and raw foods. Today, the genus Aeromonas is regarded not only as an important disease-causing pathogen of fish and other cold-blooded species, but also as the etiologic agent responsible for a variety of infectious complications in both immunocompetent and immunocompromised persons. Most of the 14 described species have been associated with human diseases. The most important pathogen is Aeromonas hydrophila that has been reported as the most predominant pathogenic bacterial species for fish aquaculture and has accountable for lesions of fish farms and high mortality rates that result in a worldwide economic crisis to the aquaculture industry (Austin, 2012, Hassan et al., 2017).

Aeromonas hydrophila are inhabitants of aquatic ecosystems and are found in most parts of the world. They can be found in fresh produce, meat, vegetables, seafood and dairy products. Infection with Aeromonas hydrophila can result in gastrointestinal infection range from diarrhea to dysentery, hemolytic syndrome, kidney disease, cellulitis, wound and soft-tissue infection, meningitis, bacteremia and septicemia ocular infections, pneumonia and respiratory tract infections, urinary tract infection in neonates, osteomyelitis, peritonitis and acute cholecystitis. Gastroenteritis typically occurs after the ingestion of contaminated water or food, whereas wound infections result from exposure to contaminated water. Invasive Aeromonas infections usually occur amongst immunocompromised individuals, primarily in patients with solid or hematologic malignancies or hepatobiliary disease, but healthy individuals may also be affected after sustaining traumatic and crush injuries, near drowning events, and burns (Janda and Abbott, 2010)

Recently, several studies showed that Aeromonas hydrophila could cause adverse effects in different organs of fish infected, where A. hydrophila indicated liver and kidney damage that can be attributed to the presence of many extracellular toxins and enzymes such as cytotoxins, hemolysins, enterotoxins and proteases that are excreted from the virulence of Aeromonas hydrophila (Abd-ElRhman, 2009, El-Barbary, 2010, Ahmad et al., 2011, Souza et al., 2016 and Dos Santos et al., 2017)

Despite the importance that Aeromonas hydrophila has gained in recent years as an etiological agent in many diseases in human, relatively few studies have examined the adverse effects of Aeromonas hydrophila on different organs functions in mammals. Moreover, until now, the effect of Aeromonas hydrophila infection on the innate, cell-mediated and humoral immunity has been rarely studied, although it is very important as it is of potential importance for the immunological control of different diseases caused by Aeromonas hydrophila in human and mammals. To date only limited information is available in understanding these immunological responses. This study, therefore, was designed to understand the immunological mechanisms underlying resistance to infection by Aeromonas hydrophila in mammals and to determine whether Aeromonas hydrophila is capable of causing biochemical alterations concerning lipid profile and liver and kidney functions in male albino rats.

\section{Material and Methods}

\subsection{Experimental Animals}

Forty (40) male healthy albino rats (Rattus norvegicus) (body weight 120 - 130gm) were included in the present study. The rats were obtained from Faculty of Medicine, Minia, Egypt. Rats were examined well to ensure that they are free from any signs of microbial or parasitic diseases. The study protocol was approved by the animal Ethics Committee of the Zoology Department at the Faculty of Science, Minia University according to Helsinki principles. The rats were housed in well aerated cages with sawdust bottom coating under hygienic condition and were provided commercial rodent diet and water ad libitum for two weeks before carrying out the experiment procedures for adaptation and housed in temperature controlled room $\left(25^{\circ} \mathrm{C}\right)$ with constant humidity and $12 \mathrm{~h} / 12 \mathrm{~h}$ light/dark cycle. 


\subsection{Bacteria}

A- 47 strain of Aeromonas hydrophila was supplied by Botany Department, Faculty of Science, Minia University. This strain was mainly identified, purified serologically and provided by Dept. of Microbiology, Faculty of Science, Al- Azhar University.

\subsubsection{Media}

Nutrient agar (PH 6.8) and nutrient broth (PH7.5-7.6) were used for the bacterial growth.

Nutrient agar (PH 6.8) consists of:

Meat peptone $5 \mathrm{~g}$, beef extract $3 \mathrm{~g}$, sodium chloride $5 \mathrm{~g}$, agar $15 \mathrm{~g}$, distilled water1000 ml.

\section{Nutrient broth (pH 7.5-7.6) contains}

Peptone $5 \mathrm{~g}$, beef extract $5 \mathrm{~g}$, sodium chloride $5 \mathrm{~g}$, and distilled water $1000 \mathrm{ml}$.

The components were autoclaved at $121^{\circ} \mathrm{C}$ for 15 minutes after they were dissolved by heating.

\subsubsection{Bacterial isolates identification:}

Colonial growth criteria, morphological and motility characteristics were used for the identification of bacteria. The identification process was performed according to Cruickshank et al. (1975). The collected were streaked on nutrient agar plates and incubated at $28^{\circ} \mathrm{C}$ for 24 hours. The well identified Aeromonas hydrophila colonies were inoculated into nutrient agar slants as stock for further phenotypic identification.

\subsubsection{Quantitative bacteriological determination:}

Numbers of bacteria were calculated according to the matching technique developed by Mc farland after some modifications by measuring the optical density of both turbidity standards and bacterial cell suspensions at 650nm (Baron et al., 1994).

\subsection{Experimental design:}

Rats were divided into four main groups, each group consisted of ten animals and subdivided into two subgroups (control and treated), each of five animals. Treated subgroups were daily injected intraperitoneally (I.P) with A. Hydrophila isolates with $0.2 \mathrm{ml}$ of one day bacterial cell suspended in sterile saline solution $(0.9 \% \mathrm{NaCl})$ equivalent to $6 \times 10^{6}$ bacterial cell $/ \mathrm{ml}$. Control subgroups received an equal dose of $0.9 \% \mathrm{NaCl}$ by the same manner. Both control and treated subgroups were sacrificed after 4,8,12 and 16 days respectively.

\subsection{Collection of blood and tissue samples:}

After each duration, rats of control and treated subgroups were sacrificed and two blood samples were immediately collected. The first sample was collected in heparinized tube $(2.25 \mu / 5 \mathrm{ml}$ blood $)$ for white blood cells, the test of migration inhibition factor (MIF) and the rest was centrifuged for 5 minutes at $3000 \mathrm{rpm}$ to separate plasma used in some biochemical studies. The second sample was collected in non-heparinized tube and allowed to clot at room temperature for separating serum stored at $\left(-80^{\circ} \mathrm{C}\right)$ for biochemical studies and some immunological tests (PFC, agglutination, precipitation and total immunoglobulin). After animal dissection, samples from spleen were fixed in phosphate buffer saline (PBS) for immunological studies (plaque and rosette forming cell assays).

\subsection{Biochemical and immunological analysis}

Serum total lipids concentration was calculated by the method described by Zollner and Kirsch (1962). Serum triglycerides concentration was determined according to the method described by Fossati and Lorenzo (1982). Total Cholesterol, LDL-cholesterol, and HDL-cholesterol concentrations were calculated in serum using the method described by Tietz (1995). Serum uric acid, urea, total protein and albumin were estimated by using diagnostic kits following the procedures followed by Olubanke (2012). The levels of serum alanine and aspartate aminotransferase (ALTandAST) were determined spectroscopically in serum according to the method of Henry (1964) and Tietz (1995)

Total Leukocyte counts and differential Leukocyte counts were measured on hematological analyzer following the procedure as mentioned by Dacie and Lewis (1984). The phagocytosis in vitro of polymorphonuclear leukocytes using Candida albicans was determined by separation of 
polymorphonuclear cells using Ficoll-histopaque-1119 and Ficollhistopaque-1077 (Sigma-diagnostics) as described by Wilkinson (1981). The phagocytic activity (in vivo) of polymorphonuclear leukocytes was determined with a phase contrast microscope according to El-Feki (1994). The cell mediated immune response was determined by carrying the immunocytoadherence (Rosette forming cell, RFC) technique as described by Ali (1987). The migration inhibition factor of leucocytes (MIF) was measured using capillary technique (Abu El- Saad, 1996). The humoral immune response was established using the plaque forming cell (PFC) technique of Kanakambica and Muthukkaruppan (1972). The detection of agglutinating antibodies was established according to the hemagglutination technique (Hudson and Hay 1980), the detection of precipitating antibodies was carried out using the double immuno- diffusion technique (Hudson and Hay 1980) and the quantitation of serum immunoglobulin was carried out by Zinc sulphate turbidity method (Pfeiffer et al.,1977).

\subsection{Statistical analysis:}

Results were represented as mean \pm standard error $(\mathrm{M} \pm \mathrm{SE})$. Student's t-test was applied in the present study, as was described by Snedecor and Cochran (1971).

\section{Results}

\subsection{Immunological studies}

In the present study, injection with Aeromonas hydrophila induced significant increase $(\mathrm{P}<0.01)$ in the total count of leucocytes at the first time interval compared with the corresponding control. On the other hand, the other three intervals exhibited decrease in the count in comparison with the corresponding control values. This decrease was significant at the second $(\mathrm{P}<0.001)$ and third $(\mathrm{P}<0.05)$ time intervals (Table 1).

The data listed in (Table 1) showed significant increase $(\mathrm{P}<0.001)$ in the number of neutrophils throughout the period of the bacterial injection in comparison with the corresponding control. On the other hand, there was a marked decrease in the number of lymphocytes all-over the experimental duration compared with the corresponding controls $(\mathrm{P}<0.001)$.

On the other hand, the recorded results in Table $(1)$ showed significant increase $(\mathrm{P}<0.05)$ in basophils and acidophils counts in comparison with the control ones. This increase was highly significant $(\mathrm{P}<0.01)$ in acidophils number at the last time interval. Also, the present data indicated an increase in the number of monocytes after bacterial injection compared to the corresponding controls, except after 8 days of injection. This increase was significant $(\mathrm{P}<0.05)$ at the last two time intervals.

Table1: Effect of intraperitoneal injection of Aeromonas hydrophila on leucocytes total and differential counts in albino rats.

\begin{tabular}{|c|c|c|c|c|c|}
\hline Variables & $\begin{array}{l}\text { Days } \\
\text { Group }\end{array}$ & 4 & 8 & 12 & 16 \\
\hline \multirow{2}{*}{ Total WBCs } & $\mathbf{C}$ & $8400.0 \pm 169.50$ & $10540.0 \pm 271.50$ & $11490.0 \pm 519.70$ & $8640.0 \pm 486.20$ \\
\hline & $\mathbf{T}$ & $10470.0 * * \pm 581.3$ & $8275.0 * * * \pm 168.90$ & $9320.0 * \pm 729.80$ & $7940.0 \pm 213.10$ \\
\hline \multirow{2}{*}{ Neutrophils\% } & $\mathbf{C}$ & $22.20 \pm 0.60$ & $20.30 \pm 0.20$ & $21.20 \pm 0.40$ & $21.10 \pm 0.40$ \\
\hline & $\mathbf{T}$ & $27.60 * * * \pm 0.20$ & $27.90 * * * \pm 0.20$ & $27.70 * * * \pm 0.30$ & $27.70 * * * \pm 0.30$ \\
\hline \multirow{2}{*}{$\begin{array}{c}\text { Lymphocytes } \\
\%\end{array}$} & $\mathbf{C}$ & $71.50 \pm 0.40$ & $73.20 \pm 0.10$ & $73.30 \pm 0.20$ & $73.20 \pm 0.40$ \\
\hline & $\mathbf{T}$ & $65.70 * * * \pm 0.40$ & $64.90 * * * \pm 0.30$ & $65.70 * * * \pm 0.30$ & $65.70 * * * \pm 0.20$ \\
\hline \multirow{2}{*}{ Basophils \% } & $\mathbf{C}$ & $0.60 \pm 0.02$ & $0.50 \pm 0.02$ & $0.50 \pm 0.04$ & $0.50 \pm 0.04$ \\
\hline & $\mathbf{T}$ & $0.70 \pm 0.04$ & $0.60 * \pm 0.04$ & $0.60 * \pm 0.03$ & $0.60 * \pm 0.03$ \\
\hline \multirow{2}{*}{ Acidophils \% } & $\mathbf{C}$ & $1.96 \pm 0.20$ & $1.90 \pm 0.09$ & $1.60 \pm 0.09$ & $1 . .40 \pm 0.09$ \\
\hline & $\mathbf{T}$ & $2.10 \pm 0.09$ & $2.20 * \pm 0.09$ & $1.90 * \pm 0.04$ & $1.90 * * \pm 0.09$ \\
\hline \multirow{2}{*}{ Monocytes\% } & $\mathrm{C}$ & $3.80 \pm 0.20$ & $4.10 \pm 0.09$ & $3.50 \pm 0.10$ & $3.80 \pm 0.09$ \\
\hline & $\mathrm{T}$ & $4.00 \pm 0.10$ & $4.00 \pm 0.09$ & $4.00 * \pm 0.09$ & $4.20 * \pm 0.10$ \\
\hline
\end{tabular}

Values are expressed as means $\pm \mathrm{SE}$

$* \mathrm{P}<0.05 \quad * * * \mathrm{P}<0.001$

Comparisons are made at each time interval between the Aeromonas hydrophila treated group $(\mathrm{T})$ and the corresponding control (C). 
The phagocytic activity of the leukocytes after bacterial injection indicated the changes which occurred in the innate immunity as the percentage of the phagocytes either in vivo or in vitro increased at all times when compared with the controls. The increase in the percentage of the phagocytes in vivo was very highly significant $(\mathrm{P}<0.001)$ and the maximal percentage was obtained after 4 days of injection. On the other hand, the in vitro phagocytic activity exhibited significant increase $(\mathrm{P}<0.01)$, $(\mathrm{P}<0.05),(\mathrm{P}<0.01)$, and $(\mathrm{P}<0.001)$ at the first, second, third and fourth time intervals respectively compared with the corresponding controls (Table 2).

Table 2: Effect of intraperitoneal injection of Aeromonas hydrophila on the phagocytic activity of albino rats.

\begin{tabular}{lccccccccc}
\hline \multirow{2}{*}{ Assays } & Days & \multicolumn{2}{c}{$\mathbf{4}$} & \multicolumn{2}{c}{$\mathbf{8}$} & \multicolumn{2}{c}{$\mathbf{1 2}$} & \multicolumn{2}{c}{$\mathbf{1 6}$} \\
\cline { 2 - 10 } In vivo & $\mathbf{C}$ & $\mathbf{T}$ & $\mathbf{C}$ & $\mathbf{T}$ & $\mathbf{C}$ & $\mathbf{T}$ & $\mathbf{C}$ & $\mathbf{T}$ \\
& 0 & $20.32^{* * *}$ & 0.38 & $12.30^{* * *}$ & 1.30 & $15.70^{* * *}$ & 1.30 & $20.50^{* * *}$ \\
\multirow{2}{*}{ In vitro } & 25.30 & 44.79 & \pm 0.76 & \pm 1.49 & \pm 1.85 & \pm 1.20 & \pm 1.70 & \pm 1.14 \\
& \pm 3.70 & \pm 5.81 & \pm 3.27 & \pm 15.21 & \pm 5.54 & \pm 11.22 & \pm 5.99 & \pm 6.20 \\
\hline
\end{tabular}

Values are expressed as means $\pm \mathrm{SE}$

$* \mathrm{P}<0.05 \quad * * \mathrm{P}<0.01 \quad * * * \mathrm{P}<0.001$

Comparisons were made at each time interval between the Aeromonas hydrophila - treated group $(\mathrm{T})$ and the corresponding control $(\mathrm{C})$.

The cell- mediated immune response was estimated by carrying the immunocytoadherence (rosette forming cell, RFC) technique and the migration inhibition factor of leucocytes (MIF). The RFC increased up to the end of the experiment $(\mathrm{P}<0.001)$ in comparison with the control values. The percentage of migration inhibition factor deceased after injection with the bacterial suspension when compared with the control values. This decrease was very highly significant $(\mathrm{P}<0.001)$ at the second and fourth time intervals and highly significant $(\mathrm{P}<0.01)$ at third time interval (Table 3$)$.

Table 3: Effect of intraperintoneal injection of Aeromonas hydrophila on the cellular immunity in albino rats.

\begin{tabular}{cccccccccc}
\hline \multirow{2}{*}{ Assays } & \multicolumn{2}{c}{$\mathbf{4}$} & \multicolumn{2}{c}{$\mathbf{8}$} & \multicolumn{12}{c}{$\mathbf{1 2}$} & $\mathbf{1 6}$ \\
\cline { 2 - 9 } & $\mathbf{C}$ & $\mathbf{T}$ & $\mathbf{C}$ & $\mathbf{T}$ & $\mathbf{C}$ & $\mathbf{T}$ & $\mathbf{C}$ & $\mathbf{T}$ \\
\hline \multirow{2}{*}{$\mathrm{PFC}$} & 0.50 & $14.21^{* * *}$ & 0.70 & $18.60^{* * *}$ & 1.02 & $21.19^{* * *}$ & 0.39 & $20.02^{* * *}$ \\
& \pm 0.88 & \pm 2.55 & \pm 1.32 & \pm 1.17 & \pm 1.33 & \pm 1.30 & \pm 0.82 & \pm 1.58 \\
\hline \multirow{2}{*}{$\mathrm{MIF}$} & 2.13 & \multirow{2}{*}{$1.08 \pm 0.57$} & 3.03 & $1.22^{* * *}$ & $1.12 \pm$ & $1.31^{* *}$ & 3.41 & $1.61^{* * *}$ \\
& \pm 0.34 & & \pm 0.81 & \pm 0.27 & 1.36 & \pm 0.32 & \pm 0.59 & \pm 0.50 \\
\hline
\end{tabular}

Values are expressed as means $\pm \mathrm{SE}$

$* \mathrm{P}<0.05 \quad * * \mathrm{P}<0.01 \quad * * \mathrm{P}<0.001$

Comparisons were made at each time interval between the Aeromonas hydrophila - treated group (T) and the corresponding control $(\mathrm{C})$.

Humoral immunity was measured herein via the plaque forming cell (PFC) assay, haemagglutination test, precipitation technique and the determination of total immunoglobulin (Ig.). The percentage of the plaque forming cells showed very highly significant increase $(P<0.001)$ during the periods of injection in comparing with the corresponding controls. Also, the agglutinating antibodies production with the bacterial antigen increased along the time intervals. This increase was very highly significant $(\mathrm{P}<0.001)$ at the first and second time intervals and highly significant $(\mathrm{P}<0.01)$ at the third and fourth time intervals. Moreover, the precipitating arc appeared in all time intervals, but it was much higher at the second time interval. Also, the total immunoglobulin of the treated rats was higher than that of the corresponding control in most time intervals, while, there was a decrease on the $12^{\text {th }}$ day compared with the corresponding control (Table 4).

\subsection{Biochemical studies:}

Table (5) demonstrates that estimation of plasma total proteins after bacterial inoculation showed a decrease in protein concentration all-over the treated subgroups. Very highly significant values $(\mathrm{P}<$ 0.001 ) were recorded after 12 and 16 days of injection compared with the corresponding controls. 
Table 4: Effect of intraperitoneal injection of Aeromonas hydrophila on the humoral immune response in albino rats.

\begin{tabular}{|c|c|c|c|c|c|c|c|c|}
\hline \multirow[b]{2}{*}{ Assays } & \multicolumn{2}{|l|}{4} & \multicolumn{2}{|l|}{8} & \multicolumn{2}{|l|}{12} & \multicolumn{2}{|l|}{16} \\
\hline & $\mathbf{C}$ & $\mathbf{T}$ & $\mathbf{C}$ & $\mathbf{T}$ & C & $\mathbf{T}$ & $\mathbf{C}$ & $\mathbf{T}$ \\
\hline \multirow{2}{*}{ PFC } & $0.50 \pm$ & $15.40 * * *$ & 0.21 & $16.42 * * *$ & 1.00 & $18.99 * * *$ & 0.60 & $20.70 * * *$ \\
\hline & 0.8 & \pm 1.81 & \pm 0.45 & \pm 1.94 & \pm 1.00 & \pm 1.14 & \pm 1.33 & \pm 1.81 \\
\hline \multirow{2}{*}{ Agglutination } & 3.00 & $5.00 * * *$ & 4.00 & $9.00 * * *$ & $4.00 \pm$ & $8.00 * *$ & 4.00 & $6.00 * *$ \\
\hline & \pm 4.41 & \pm 1.30 & \pm 3.20 & \pm 0.40 & 2.50 & \pm 1.70 & \pm 2.00 & \pm 2.40 \\
\hline \multirow{2}{*}{ Total Ig } & 15.40 & 20.99 & 15.78 & 26.31 & 17.41 & 15.72 & 14.89 & 23.23 \\
\hline & \pm 2.59 & \pm 8.91 & \pm 4.19 & 9.84 & \pm 6.62 & \pm 8.52 & \pm 1.88 & \pm 8.99 \\
\hline Precipitation & - & $+\mathrm{Ve}$ & - & $++\mathrm{Ve}$ & - & $+\mathrm{Ve}$ & - & $+\mathrm{Ve}$ \\
\hline
\end{tabular}

Values are expressed as means $\pm \mathrm{SE}$

$* \mathrm{P}<0.05 \quad * * \mathrm{P}<0.01 \quad * * * \mathrm{P}<0.001$

Comparisons were made at each time interval between the Aeromonas hydrophila - treated group (T) and the corresponding control $(\mathrm{C})$.

Table 5: Effect of intraperitoneal injection of Aeromonas hydrophila on plasma total proteins and albumin concentrations in albino rats.

\begin{tabular}{lcllll}
\hline Variables & $\begin{array}{c}\text { Days } \\
\text { Group }\end{array}$ & $\mathbf{4}$ & $\mathbf{8}$ & $\mathbf{1 2}$ & $\mathbf{1 6}$ \\
\hline \multirow{2}{*}{ Total proteins (g/dl) } & $\mathbf{C}$ & $7.23 \pm 0.20$ & $6.70 \pm 0.20$ & $6.80 \pm 0.20$ & $6.90 \pm 0.10$ \\
& $\mathbf{T}$ & $6.60 \pm 0.40$ & $6.40 \pm 0.30$ & $3.90^{* * *} \pm 0.50$ & $4.20^{* * *} \pm 0.20$ \\
\hline \multirow{2}{*}{ Albumin (g/dl) } & $\mathbf{C}$ & $3.60 \pm 0.20$ & $3.50 \pm 0.20$ & $3.60 \pm 0.20$ & $3.60 \pm 0.20$ \\
& $\mathbf{T}$ & $1.80^{* * *} \pm 0.04$ & $2.50^{* * *} \pm 0.10$ & $2.80^{* * *} \pm 0.10$ & $2.90^{* * *} \pm 0.10$ \\
\hline
\end{tabular}

Values are expressed as means $\pm \mathrm{SE}$

$* \mathrm{P}<0.05 \quad * * \mathrm{P}<0.01 \quad * * * \mathrm{P}<0.001$

Comparisons were made at each time interval between the Aeromonas hydrophila - treated group (T) and the corresponding control (C).

Also, the present data showed a decrease in albumin concentration all-over the treated subgroups compared with the corresponding controls. This decrease was very highly significant $(\mathrm{P}<0.001)$.

Total lipids content of serum tended to increase with the continuous injection of bacteria. All treated subgroups had higher lipids concentrations than the control except the first subgroup (Table 6). This subgroup value had a significant decrease $(\mathrm{P}<0.05)$ compared to the control. A very highly significant increase $(\mathrm{P}<0.001)$ in concentration was recorded after eight days of the inoculation compared to the corresponding control.

As regard total cholesterol concentration, the first subgroup showed a very highly significant decrease $(\mathrm{P}<0.001)$, while the $2^{\text {nd }}$ and the last ones had very highly significant increases $(\mathrm{P}<0.001)$, over the control (Table 6 ). The value of the $3^{\text {rd }}$ subgroup had nearly located at the range of the control value and was non-significant values.

Concerning HDL concentrations after the Aeromonas injection (Table 6), very highly significant decrease $(\mathrm{P}<0.001)$ was obtained after 4 days of inoculation. This decrease was highly significant $(\mathrm{P}<$ $0.01)$ at the third time interval. On the other hand, the second time interval treated subgroup showed a highly significant increase $(\mathrm{P}<0.01)$ in HDL in comparison with the corresponding control. Also, the fouth time interval treated subgroup showed very highly significant increase $(P<0.001)$ in HDL in comparison with the corresponding control.

In contrast to the results of HDL, LDL cholesterol values increased at different periods of Aeromonas injection, when compared with the controls (Table 6). This increase was significant $(\mathrm{P}<$ 0.05 ) at the second and fourth time intervals compared to the corresponding controls.

Control and treated concentrations of serum triglycerides were recorded in Table (6), showing the differences occurred after the Aeromonas injection. The first treated subgroup showed a highly significant decrease $(\mathrm{P}<0.01)$ in comparison with the corresponding control. Conversely, the second time interval treated subgroup showed a highly significant increase $(\mathrm{P}<0.01)$ in comparison with the corresponding control. 
Table 6: Effect of intraperitoneal injection of Aeromonas hydrophila on total lipids, total cholesterol, HDL-cholesterol, LDL-cholesterol and triglycerides in albino rats.

\begin{tabular}{|c|c|c|c|c|c|}
\hline Variables & $\begin{array}{c}\text { Days } \\
\text { Group }\end{array}$ & 4 & 8 & 12 & 16 \\
\hline \multirow{2}{*}{ Total lipids (g/l) } & $\mathbf{C}$ & $1.40 \pm 0.20$ & $1.50 \pm 0.30$ & $1.50 \pm 0.20$ & $1.60 \pm 0.20$ \\
\hline & $\mathbf{T}$ & $0.60 * \pm 0.20$ & $3.30^{* * *} \pm 0.30$ & $2.00 \pm 0.30$ & $2.40 * \pm 0.30$ \\
\hline \multirow{2}{*}{$\begin{array}{l}\text { Cholesterol } \\
(\mathrm{mg} / \mathrm{dl})\end{array}$} & $\mathbf{C}$ & $116.40 \pm 5.30$ & $111.30 \pm 5.30$ & $114.30 \pm 3.90$ & $112.40 \pm 5.20$ \\
\hline & $\mathbf{T}$ & $65.50 * * * \pm 7.80$ & $154.60 * * * \pm 6.40$ & $100.00 \pm 6.40$ & $163.60 * * * \pm 6.40$ \\
\hline \multirow{2}{*}{ HDL (mg/dl) } & $\mathbf{C}$ & $55.60 \pm 2.90$ & $55.50 \pm 3.30$ & $55.80 \pm 2.80$ & $56.00 \pm 3.00$ \\
\hline & $\mathbf{T}$ & $13.80 * * * \pm 1.90$ & $73.70 * * \pm 3.20$ & $38.50 * * \pm 2.70$ & $80.30 * * * \pm 2.90$ \\
\hline \multirow{2}{*}{ LDL (mg/dl) } & $\mathbf{C}$ & $39.20 \pm 3.40$ & $35.90 \pm 3.00$ & $39.20 \pm 3.10$ & $37.70 \pm 2.90$ \\
\hline & $\mathbf{T}$ & $40.90 \pm 5.50$ & $50.90 * \pm 5.80$ & $43.50 \pm 3.60$ & $59.30 * \pm 7.70$ \\
\hline \multirow{2}{*}{$\begin{array}{l}\text { Triglycerides } \\
\text { (mg/dl) }\end{array}$} & $\mathbf{C}$ & $108.00 \pm 5.80$ & $108.00 \pm 5.80$ & $100.00 \pm 7.10$ & $110.00 \pm 7.10$ \\
\hline & $\mathbf{T}$ & $54.00 * * \pm 9.30$ & $150.00 * * \pm 7.10$ & $90.00 \pm 7.10$ & $120.00 \pm 7.10$ \\
\hline
\end{tabular}

Values are expressed as means $\pm \mathrm{SE}$

$* \mathrm{P}<0.05 \quad * * \mathrm{P}<0.01 \quad * * * \mathrm{P}<0.001$

Comparisons were made at each time interval between the Aeromonas hydrophila - treated group (T) and the corresponding control $(\mathrm{C})$.

Table (7) demonstrates the effect of the Aeromonas inoculation on the activity of serum AST. AST activity was gradually decreased during the different time intervals comparing to the controls. This decrease was significant $(\mathrm{P}<0.05)$ at the first and second time intervals, highly significant $(\mathrm{P}<0.01)$ at the third time interval and very highly significant $(\mathrm{P}<0.001)$ at the fourth time interval. Also, the present data revealed significant decrease in ALT activity during the different time intervals compared to the controls with the bacterial inoculation. This decrease was very highly significant $(\mathrm{P}<0.001)$ at the first time interval, highly significant $(\mathrm{P}<0.01)$ at the third time interval and significant $(\mathrm{P}<0.05)$ at the second and fourth time intervals compared to the control one.

Table 7: Effect of intraperitoneal injection of Aeromonas hydrophila on serum AST and ALT activity in albino rats.

\begin{tabular}{lcllll}
\hline Variables & $\begin{array}{c}\text { Days } \\
\text { Group }\end{array}$ & $\mathbf{4}$ & $\mathbf{8}$ & $\mathbf{1 2}$ & $\mathbf{1 6}$ \\
\hline AST & $\mathbf{C}$ & $0.48 \pm 0.03$ & $0.47 \pm 0.04$ & $0.47 \pm 0.04$ & $0.47 \pm 0.03$ \\
(unit/ml) & $\mathbf{T}$ & $0.38^{*} \pm 0.03$ & $0.36^{*} \pm 0.03$ & $0.37 * * \pm 0.01$ & $033^{* * * \pm 0.02}$ \\
\hline ALT & $\mathbf{C}$ & $0.97 \pm 0.02$ & $0.95 \pm 0.03$ & $0.98 \pm 0.01$ & $0.97 \pm 0.03$ \\
(unit/ml) & $\mathbf{T}$ & $0.73^{* * *} \pm 0.04$ & $0.76^{*} \pm 0.05$ & $0.79 * * \pm 0.05$ & $0.79^{*} \pm 0.05$ \\
\hline
\end{tabular}

Values are expressed as means $\pm \mathrm{SE}$

$* \mathrm{P}<0.05 \quad * * \mathrm{P}<0.01 \quad * * \mathrm{P}<0.001$

Comparisons were made at each time interval between the Aeromonas hydrophila - treated group (T) and the corresponding control $(\mathrm{C})$

Bacterial inoculation exhibited significant increase in serum urea all-over the treated subgroups compared with the corresponding controls. This increase was very highly significant $(\mathrm{P}<$ 0.001 ) at the second, third, and fourth time intervals. Also, serum uric acid concentrations showed a very highly significant increase $(\mathrm{P}<0.001)$ along the periods of injection in all subgroups, when compared with the control ones( Table 8).

Table 8: Effect of intraperitoneal injection of Aeromonas hydrophila on blood urea and uric acid in albino rats.

\begin{tabular}{lcllll}
\hline Variables & $\begin{array}{c}\text { Days } \\
\text { Group }\end{array}$ & $\mathbf{4}$ & $\mathbf{8}$ & $\mathbf{1 2}$ & $\mathbf{1 6}$ \\
\hline Urea & $\mathbf{C}$ & $60.40 \pm 6.70$ & $59.70 \pm 5.50$ & $57.00 \pm 5.50$ & $60.60 \pm 5.20$ \\
$\mathbf{( m g / d l )}$ & $\mathbf{T}$ & $88.10 \pm 11.80$ & $141.80^{* * * \pm 14.80}$ & $141.80 * * * \pm 10.60$ & $130.00^{* * * \pm 6.90}$ \\
\hline Uric acid & $\mathbf{C}$ & $2.00 \pm 0.10$ & $2.00 \pm 0.10$ & $2.20 \pm 0.10$ & $2.10 \pm 0.10$ \\
$(\mathbf{m g} / \mathbf{d l})$ & $\mathbf{T}$ & $4.900^{* * *} \pm 0.40$ & $5.40^{* * * \pm 0.30}$ & $6.20 * * * \pm 0.30$ & $5.60 * * * \pm 0.50$ \\
\hline
\end{tabular}

Values are expressed as means $\pm \mathrm{SE}$

$* \mathrm{P}<0.05 \quad * * \mathrm{P}<0.01 \quad * * * \mathrm{P}<0.001$

Comparisons were made at each time interval between the Aeromonas hydrophila - treated group (T) and the corresponding control (C). 


\section{Discussion}

Aeromonas hydrophila is a pathogenic organism that causes a broad spectrum of diseases in humans and animals. While it was thought to be an opportunistic pathogen in humans, a growing number of intestinal and extra-intestinal cases of disease indicate that Aeromonas hydrophila is an emergent human pathogen, irrespective of the immunological aspects of the host. An increasing number of reports have implicated Aeromonas species as the etiologic agent in acute diarrhea and in wound and skin injuries, indicating that these organisms are more important than previously thought. Aeromonas species produce a variety of virulence factors, including hemolysins, enterotoxins, cytotoxins and adhesins, that have been implicated in the pathogenicity of bacteria. A cytotoxic enterotoxin also known as 'aerolysin', which has enterotoxic, cytotoxic and hemolytic activities, has been described as the most powerful virulence factor associated with Aeromonas-mediated gastrointestinal illnesses (Igbinosa et al., 2012 and Liu et al., 2017).

The present study demonstrated that, during the last three time intervals, the leucocytes showed a continuous decrease in number in response to the bacterial injection compared with the control, which might have been due to the failure of the haemopoietic tissue in supplying the blood circulation with mature leucocytes. Such effects may be due to a possible inhibitory action of the bacterial toxins and/ or due to the requirement of these cells in the inflammatory reaction due to the bacterial injection (Anitra and Silvia, 2017).

The neutrophils showed a marked increase in number all-over the experimental duration in response to the bacterial injection. This increase may be due to the stress accompanied with bacterial injection and the rapid cell proliferation. Neutrophils are harbored elsewhere in the body pre-stress and empty post- stress. In addition, neutrophils increase may be due to their phagocytic activity. Furthermore, neutrophils count may elevate after the bacterial injection since their azurophilic granules have bactericidal- permeability increasing protein that inhibits the biological activity of LPS (El-Feki et al., 2003).

The present results showed a clarified depletion in the lymphocytic count all-over the experimental duration in response to bacterial injection compared to the controls. This may be due to the lymphocyte arrest phenomenon, i.e. an inhibition of their release into the blood due to two reasons: (1) the increase of the density of the lymphocyte- like cells, and (2) a massive proliferation that could justify the increase in their mean percentage. A previous study postulated that LPS in the bacterial cell walls induces the depletion of the lymphocytes in the lymphoid organs in LPS- sensitive mice not in LPS- resistant mice. Also, lymphocytic decrease is probably attributed to the fact that lymphocytes are responsible for achieving specific defense mechanisms against bacterial pathogen (Norimatsu et al., 1995 and Marshall et al., 2018).

The present results showed a marked change in the number of basophils after bacterial injection compared with the control, as there was an insignificant increase in the first subgroup followed by a significant increase in the last three ones. This increase may be attributed to the allergy induced by the antigen (El-Feki et al., 2000). Acidophile is a component of the innate immune system that has a variety of functions, including defense against intracellular bacteria. The net effect of acidophiles is to dampen down the inflammatory response induced by microbial infection. Consequently, the increased number of acidophiles all-over the experiment duration compared with the control in the present study may be due to the engagement of these cells in defensive processes against the antigen (Kay, 2015).

Regarding the monocytes count, the infected rats showed a marked increase in monocytes count compared with the control. This increase may be due to the increase in haemopoietic activity after the exocytosis done by monocytes after the discharge of their granules to lyse the antigen extracellulary. It may be, also, due to the stress factor that accompanied injection or due to the chemotactic response to the lipid rich material of the bacterial LPS. Monocytes have the ability to modify, deacylate and dephosphorylate the chemical nature of the LPS moieties (Lipid A, Oligosaccharide core and O- chain) and alter the reactivity of these molecules against specific antibodies (Forestier et al., 1999 Rott et al., 1985).

Phagocytosis, a critical early event in the microbicidal response of neutrophils, is now appreciated to serve multiple functions in a variety of cell types. Professional phagocytes play a central role in innate immunity by eliminating pathogenic bacteria, fungi and malignant cells, and contribute to adaptive immunity by presenting antigens to lymphocytes. It is the main mechanism for the destruction of bacterial pathogens in mammals (Lim et al., 2017). The current study showed increased 
phagocytic index in all treated rats in response to bacterial infection and this may be related to the induction of the phagocytic and killing activity of macrophages and neutrophils which caused by the increased LPS on bone marrow and spleen cells (Saito Taki and Nakano, 1982, Anitra and Silvia, 2017). The increase in the phagocytic activity either in vivo or in vitro may be attributed to the ability of the macrophage to deacylate and dephosphorylate the lipid A moiety of the enterobacterial LPS accumulating within them. Also, macrophages degraded the O-antigen chain and the core oligosaccharide of the enterobacterial lipopolysaccharides. Also, the elevated phagocytic index may be due to the increase of the neutrophils released from marginated vascular endothelium as a result of early defense against antigen infection. In addition, the production of $\mathrm{C}$ - reactive protein (CRP) activates macrophages, and has an opsonizing effect on the phagocytosis. Furthermore, the increase in the phagocytic activity may be related to the increase in the endotoxin - coated RBCs debris as a result of the action of bacterial haemolysin or other bacterial factors as phospholipase (Abu-El-Saad, 1996, Forestier et al., 1999, Steele et al., 1987, Kodama et al., 1989 and Marshall et al., 2018).

The results of the humoral immune response of albino rat, after the bacterial injection, demonstrated that PFC, RFC agglutinating antibodies, total immunoglobulin and precipitating antibodies increased all-over the experimental period. The increase in most of the immune assays may be due to the antigenic challenge, which may in turn be due to the secretion of interferon or to the secretion of interleukin (IL-1), the lymphocyte activating factor or may be due to the secretion of Bcell growth factor by macrophages which synergies with IL-I in B- cell activation (El-Feki et al., 1999).

The elevated agglutinating titres following the bacterial infection were recorded as a result of the continuous stimulation of the antibodies by the T-independent nature of certain components found in Aeromonas hydrophila. It may also be attributed to the elevation in the total immunoglobulin level demonstrated here (Abu El-Saad; 2001, Bonilla and Oettgen, 2010).

The increased level of total immunoglobulin in Aeromonas treated rats may be due to the fact that B- cells, complement and natural antibodies are the most effective components for host survival (Bachmann and Kopf, 1999). Also, the activation of classical pathway of the complement activity in fish requires antigen - antibody interaction to recognize bacterial surface antigens. Thus, the elevated immunoglobulin level may be due to their binding to the surface component of the gram- negative bacteria, and their ability to overcome the resistance to serum killing activity of the complement. Also, this elevation of the total immunoglobulin level may be due to the fact that LPS interaction with the cellular components leads to the polyclonally activation of the B-cell subsets and secretion of the immunoglobulin (Boesen et al., 1999).

The weak results of the precipitation test might be due to the fact that the antigen used is a molecular antigen not a soluble one and it would be expected to have lower titre of precipitating factors in the infected sera when compared to the control one. Also, it may be attributed to the presence of high molecular weight of LPS that is strongly mitogenic and may have an adverse effect on the immune response (Abu El-Saad, 1996, Bonilla and Oettgen, 2010).

In the present study, the biochemical investigations revealed high decrease in plasma total proteins level at all experimental periods. These results came parallel to the findings of El-Barbary (2017) and Abu El-Saad (2001) who recorded that the decrease in plasma total proteins level to fall to about the half of its baseline values in septicaemia infection came with aeromonas hydrophila infection. The low total proteins content may be due to the hepatic dysfunction, increased capillary permeability for plasma proteins, or its degradation by the proteolytic enzymes releasing from the endothelial cells that were destroyed by the bacterial endotoxin (Stoskopf, 1993).

Karima et al., (1999) mentioned that neutrophils which were activated by LPS secrete nitric oxide (NO) that has a direct effect on various enzymes containing an iron - sulpher moiety in their catalytic center. Such enzymes include ribonucleotide reductase (necessary for DNA synthesis) and several mitochondrial enzymes that are essential for cell survival. Also, they added that once they become adherent to the endothelial cells, neutrophils transmigrate through them and release various proteases as reactive oxygen species (ROSs) and neutrophil elastase. The latter is a serine protease that degrades a variety of humoral and structural proteins, e.g. transport protein, cell receptors, membrane protein, fibronectin elastin and collagen.

Plasma albumin concentration of the treated rats exhibited more or less similar behavior pattern as total protein concentration. These results came parallel to the findings of El-Barbary (2017). It was reported that hypoalbuminemia may occur in cases of synthesis inhibition due to liver disease. In such 
cases, it is a result of inflammation or due to the increased protein catabolism under stress conditions and infection. Malabsorption may cause a mild decrease in albumin production, or glomerular disease, and albuminuria because glomerulopathy is occasionally associated with significant globulin loss (Benjamin, 1984).

By the estimation of lipids and their derivatives, results revealed that there was an increase in the level of total lipids except for first subgroup. Total cholesterol, HDL and triglycerides decreased after 4 days of injection, then, they showed significant increase after the second and third time intervals. However, LDL concentrations showed an increase all-over the experimental period. During phagocytosis of microbial intruders including bacteria, polymorphonuclear leucocytes (phagocytes) of the innate immune response increase their consumption of molecular oxygen. Neutrophils which were activated by LPS secrete nitric oxide (NO) and generate highly unstable oxygen- derived free radicals such as superoxide anion $\left(\mathrm{O}_{2}\right)$ (Karima et al., 1999). Release of these radicals may cause damage to tissue components. Also, these free radicals are responsible for the metabolic disturbances correlated with serum cholesterol and low density lipoproteins (Ludwig et al., 1982).

The effect of A. hydrophila was studied herein on the activity of serum transaminase enzymes. The results obtained indicated significant decrease of serum AST and ALT activity for treated animals all-over the period of injection. These results came in contrast with the findings of (El-Barbary, 2017) and (Brenden and Huizinga, 1986) who investigated the pathophysiological changes in mice given intramuscular inoculation of A. hydrophila. They recorded that the liver enzymes AST and ALT increased, beginning at $2 \mathrm{~h}$ and reaching their maxima at $24 \mathrm{~h}$. they reported that this increase may be due to changes in cell membrane permeability during the first $11 \mathrm{~h}$. They also added that the high activities recorded at 11, 12, 24 and $36 \mathrm{~h}$ may reflect the release of enzymes from tissue damaged by anoxia. However, decreased values of AST and ALT herein came parallel to the suggestion of Filkins (1969) who reported that long and severe endotoxaemia impairs liver function by damaging the vasculature. Also, it may be attributed to the alteration of liver cells metabolism and the multiple membrane damage inducing an important metabolic disturbances (Vergani et al., 1999).

The present results showed significant increase in the blood urea nitrogen and uric acid concentrations along the experimental period. Such increased blood urea nitrogen concentrations agreed with the results recorded by (El-Barbary, 2017) and (Brenden and Huizinga, 1986). They reported that the increased BUN levels may be due to the suppressed kidney function induced by bacterial injection since they observed congested and edematous renal tissue in the histological sections that alter the membrane permeability. However, it was reported that the cause of immunological and biochemical alterations and disturbances in lipid profile and liver and kidney functions may be due to the presence of some extracellular toxins such as cytotoxins, hemolysin, protease, enterotoxins and elastase produced by A. hydrophila (Monir et al., 2020, Liu et al., 2017, El-Barbary, 2010, Salvat et al, 2019 and Hassan et al., 2020).

\section{Conclusion}

From the previous results, we can conclude that Aeromonas hydrophila infection could affect the innate, cell-mediated and humoral immunity in mammals and that Aeromonas hydrophila is capable of causing biochemical alterations concerning lipid profile and liver and kidney functions in male albino rats. Moreover, the complications and diseases accompanied with Aeromonas septicaemia may be attributed to the immunological and biochemical changes resulted from the bacterial infection, so, the use of immuno-modulator is necessary in treatment besides the antibacterial drugs.

\section{References}

Abd-El-Rhman, A.M.M., 2009. Antagonism of Aeromonas hydrophila by propolis and its effect on the performance of Nile Tilapia, Oreochromis niloticus. Fish Shellfish Immunol., 27: 454-459.

Abu El-Saad A.S.A, 1996. Pathogenicity of Aeromonas hydrophila against common carp Cyprinus carpio. M.SC. Thesis, Fac. Sci., Minia Univ., Egypt.

Abu El-Saad, A.S., 2001. Immunological studies on albino rats against some biological toxic antigens. $\mathrm{Ph}$. D. thesis, Cairo University, Beni-Suef branch, Beni-Suef, Egypt. 
Ahmad, M.H., A.M.D. El Mesallamy, F. Samir and F. Zahran, 2011. Effect of cinnamon (Cinnamomum zeylanicum) on growth performance, feed utilization, whole-body composition and resistance to Aeromonas hydrophila in Nile tilapia. J. Applied Aquacult., 23: 289-298.

Ali, H.M., 1987. The Histogensis of lymphoid organs in Tilapia mossanbica and antibody responses in adults and frv. Ph. D. University of Aston. Birmingham, England.

Alvarez, F.P.A.B., F.B. Bianchi, N. Tygstrup, D. Vergani, and M. Zeniya, 1999. Review of criteria for diagnosis of autoimmune hepatitis. Journal of Hepatology, 31(5): 929-938.

Auer, G.K., and D.B. Weibel, 2017. Bacterial Cell Mechanics. Biochemistry, 56(29): 3710-3724.

Austin, D.A.A., 2012. Aeromonadaceae representative (Aeromonas salmonicida), Bacterial Fish Pathogens, 147-228.

Bachmann, M.F.M. Barner, and M. Kopf, 1999. CD2 sets quantitative thresholds in T cell activation. Exp Med, 190(10): 1383-92.

Baron, E.J., L.R. Peterson, and S.M. Finegold, 1994. Methods for testing antimicrobial effectiveness. In: Bailey and Scott's diagnostic microbiology, 9th ed. 168-193.

Batirel, A., S. Ozer, and S. Çolakoğlu, 2011. Nosocomial infections and risk factors in the intensive care unit of a teaching and research hospital: a prospective cohort study. Med Sci Monit., 17(5): 29-34.

Benjamin, M.M., 1984. Outline of Veterinary Clinical Pathology. 4th printing, 123-129.

Bonilla, F.A. and H.C. Oettgen, 2010. Adaptive immunity. J Allergy Clin Immunol.; 125(Suppl 2): S33-40.

Cruichshank, R., J. Duguid, B. Maanino and R. Swain, 1975. The practice of medical microbiology. 10th Ed. Churchil livingstone. London and New York.

Dacie, J., and S. Lewis, 1984. Estimation of plasma haemoglobin. In B. J. Bain, I. Bates, and M. A. Laffan (Eds.), Practical haematology (6th ed, 139-140).

Dos Santos, A.C., F.J. Sutili, B.M. Heinzmann, M.A. Cunha, I.C.M. Brusque, B. Baldisserotto and C.C. Zeppenfeld, 2017. Aloysia triphylla essential oil as additive in silver catfish diet: Blood response and resistance against Aeromonas hydrophila infection. Fish Shellfish Immunol., 62: 213-216.

El-Barbary, M.I., 2010. Some clinical, microbiological and molecular characteristics of Aeromonas hydrophila isolated from various naturally infected fishes. Aquacult. Int., 18: 943-954.

El-Feki, M.A., Z.A. Radwan and H.M. El-Fayoumi, 1999. Fish immune response against heterogeneous antigens. Egypt. J. Aquat. Biol. and Fish, 3(4): 473-491.

El-Feki, M.A., 1994. The role of chemoattractants in phagocytosis of catfish. Bull. Fac. Sci., 23(2): 185-200.

Fossati P., and P. Lorenzo, 1982. Serum Triglycerides determined colorimetrically with an enzyme that produces hydrogenperoxide. Clin. Chem., 28: 2077 - 2080.

Moustafa, E., H. Kishio, and M.A.H. Mortada, 2003. Chemotactic and chemokinetic activities of Saprolegnia parasitica toward different metabolites and fish tissue extracts. Mycoscience, 44(2): 0159-0162.

Hassan, M., E.A. Noureldin, M.A. Mahmoud, and N.A. Fita, 2017. Molecular identification and epizootiology of Aeromonas veronii infection among farmed Oreochromis niloticus in Eastern Province. KSA. Egypt, J. Aqua. Res., 43: 161-167.

Hassan, M.A.A., E. Mansour, and W. Monir, 2020. Prevalence and antibiotic Susceptibility of bacterial pathogens implicating the mortality of cultured Nile Tilapia Oreochromis niloticus, Egypt J. Aquac. 10: 23-43.

Henriette, T.B., K. Pedersen, J.L. Larsen, C. Koch, and A.E. Ellis, 1999. Vibrio anguillarum Resistance to Rainbow Trout (Oncorhynchus mykiss) Serum: Role of O-Antigen Structure of Lipopolysaccharide. Molecular and Cellular Pathogenesis, 67(1): 294-301.

Henry, R.J., 1964. Clinical Chemistry, Principles and Techniques. Hoeber Medical, Harper-Row, 190.

Hormozi, S.F., N. Vasei, M. Aminianfar, M. Darvishi, and A.A. Saeedi, 2018. Antibiotic resistance in patients suffering from nosocomial infections in Besat Hospital. Eur. J. Transl. Myol., 28(3): 7594.

Hu, X., T. Ying, L. Fenghui , L. Yushuang, Y. Pinhong, W. Wenbin, J. Jigang, L. Na, H. Qing, L. Fei , and L. Lianggvo , 2017. The effect of Aeromonas hydrophila infection on the non- 
specific immunity of blunt snout bream (Megalobrama amblycephala). Cent. Eur. J. Immunol., 42(3): 239-243.

Hudson, L. and F.C. Hay, 1980. Practical Immunology, 2nd Edition. Bdition. Blackwell Scientific Publications, Oxford.

Igbinosa, I.H., E.U. Igumbor, F. Aghdasi, et al., 2012. Emerging aeromonas species infections and their significance in public health. Sci World J., 1-13.

James, P.F., 1969. Hepatic Vascular Response to Endotoxin. Experimental Biology and Medicine, 131(4).

Janda, J.M., and S.L. Abbott, 2010. The genus Aeromonas: taxonomy, pathogenicity, and infection. Clin Microbiol Rev, 23:35-73.

Kanakambika, P. and V. Muthukkaruppan, 1972. Immunological competence in the Newly Hatched Lizard, Calotes versicolar. Proc. Soc. Exp. Biol. Med., 140: 21-23.

Karima, K., S. Matsuraoto, H. Higashi, and K. Matsushima, 1999. The molecular pathogenesis of endotoxin shock and organ failure. Mol. Med. Today, 123-132.

Kay, A., 2015. The early history of the eosinophil. Clin. Exp. Allergy, 45(3): 575-582.

Kodama, H., F. Yamada, T. Murai, Y. Nakanishi, T. Mikami and H. Izawa, 1989. Activation of trout macrophages and production of CRP after immunization with Vibrio anguillarum. Develop. Comp. Immunol. 13L 123-132.

Lim, J.J., S. Grinstein, and Z. Roth, 2017. Diversity and versatility of phagocytosis: roles in innate immunity, tissue remodeling, and homeostasis. Front Cell Infect Microbiol, 7:191.

Livermore DM, 2012. Current epidemiology and growing resistance of gram-negative pathogens. Korean J. Intern. Med., 27(2):128-42.

Ludwig, P.D., B. Hunninghake, and J.R. Hoidal, 1982. Increased leucocyte oxidative metabolism in hyperlipoproteinaemia. Lancet, 2(8294): 348-50.

Lutgring J.D. Carbapenem-resistant Enterobacteriaceae, 2019. An emerging bacterial threat. Semin. Diagn. Pathol., 36:182-186.

Manal, I.E., 2017. Serum Biochemical and Histopathological Changes Associated with Aeromonas hydrophila Isolated from Oreochromis niloticus and Sparus aurata with Multiple Antibiotic Resistance Index. Journal of Biological Sciences, 17: 222-234.

Manning, M.J. and M.F. Tanter, 1985. Fish Immunology. Academic Press.

Moustafa, E., H. Kishio , and M.A.H. Mortada, 2003. Chemotactic and chemokinetic activities of Saprolegnia parasitica toward different metabolites and fish tissue extracts. Mycoscience, 44(2): 0159-0162.

Naas, T., L. Dortet, and B.I. Iorga, 2016. Structural and Functional Aspects of Class A Carbapenemases. Curr Drug Targets, 17(9):1006-28.

Norimatsu, M.T.O., A. Aoki, and K. Ohishi, 1995. Lipopolysaccharide-induced apoptosis in swine lymphocytes in vivo. Infection and Immunity, 63(3):1122-6.

Olubanke, O., 2012. Phytochemical, biological and toxicological studies of extracts of young twigs and leaves of gray Nicker nut (Caesalpinia bonduc (Linn) Roxb. Covenant University.

Pfeiffer, N.E., T.C. McGuire, R.B. Bendel and J.M. Weikel, 1977. Quantitation of bovine Immuno globulins: Comparison of single radial immune- diffusion, Zinc sulphate turbidity, Serum Electrophoresis, and Refractomter Methods. Am. J. Vet. Res, 38 (S): 693- 698.

Rita, A.B. and H.W. Huizinga, 1986. Pathophysiology of experimental Aeromonas hydrophila infection in goldfish, Carassius auratus. Journal of Fish Diseases, 9(2):163 - 167.

Roitt, I.M., J. Brostoff, and D. Male, 1985. Immunology. 5th ed., Churchill Livingstone, Edinburg, London, New York.

Ruppé, É., P.L. Woerther, and F. Barbier, 2015. Mechanisms of antimicrobial resistance in Gramnegative bacilli. Ann Intensive Care, 5(1):61.

Sabine, F.B., J. Bernard, and F. Christiane, 1999. Consequences of Reduction of Klebsiella pneumoniae Capsule Expression on Interactions of This Bacterium with Epithelial Cells. Molecular and Cellular Pathogenesis, 67(2): 554-561.

Saito, T.T. and M. Nakano, 1982. Activation of bone marrow (B.M) cells by bacterial lipopolysaccharides (LPS) and microorganisms. In: "Immuno - modulation by microbial products and related synthetic compounds." Yamamura Y, Kotani S, Azuma L, Koda Aand Shba T (Eds.): Exp. Med. 299-302. 
Salvat, M.J.F.A., and N. Aeromonas, 2019. In Global Water Pathogen Project; University of Alberta: Edmonton, AB, Canada.

Snedecor, G.W. and Cochran, 1971. Statistical methods, 14th ED. Iowa State Univ. Press.

Souza, C.F., M.D. Baldissera, R.A. Vaucher, L.Q.S. Lopes and B.S. Vizzotto et al., 2016. In vivo bactericidal effect of Melaleuca alternifolia essential oil against Aeromonas hydrophila: Silver catfish (Rhamdia quelen) as an experimental model. Microb. Pathog., 98: 82-87.

Steele, R.W., C.R. Steed, N.S. PIllington and R.K. Charlton, 1987. Functional Capacity of migrated and bone marrow reserve grandcoytes. Infect. Immanol., 55: 2359-2363.

Stoskopf, M.K., 1993. The reports of lesions in kidney and intestine of apparently normal cultured silver carp. Advances in Bioscience and Biotechnology, 3 (2).

Tietz, N.W., 1995. Clinical Guide to Laboratory tests. 3rd ed. Philadelphia. WB. Saunders, 268-273.

Van Duin, D., 2017. Carbapenem-resistant Enterobacteriaceae: What we know and what we need to know. Virulence, 8:379-382.

Walid, M., A.A. Mohamed , H. Saad El-Din , M. El Sayed, M.M. A. Somayah , 2020. Pomegranate peel and moringa-based diets enhanced biochemical and immune parameters of Nile tilapia against bacterial infection by Aeromonas hydrophila. Microb Pathog, 145:104202.

Wilkinson, P.C., 1981. Techniques in Clinical Immunology. 2nd Ed., Scientific Publication, London. 287-288.

Zollner, N., and K. Kirsch, 1962. Determination of serum total lipids calorimetrically. Z. ges. exp. Med., 135: 545. 